\title{
Statistical Analysis of the Role of Internal Audit in Promoting Good Governance in Public Institutions in Kenya
}

\author{
Kennedy Sakaya Barasa \\ Department of Statistics and Actuarial Sciences, Jomo Kenyatta University of Science and Technology, Nairobi, Kenya
}

Email address:

sakayak33@gmail.com

To cite this article:

Kennedy Sakaya Barasa. Statistical Analysis of the Role of Internal Audit in Promoting Good Governance in Public Institutions in Kenya. Journal of Investment and Management. Vol. 4, No. 1, 2015, pp. 38-46. doi: 10.11648/j.jim.20150401.16

\begin{abstract}
Internal Auditing has increasingly been recognized as an integral part of modern control structures and governance practices in both the private sector and public service. It has also been adding value in organizations across all sectors for many years in order to fight against the global financial crisis and recent cases of corporate frauds that have brought into sharp focus the consequence of the precarious role to be played by the internal auditors in ensuring good corporate governance. The main objective of this study was to find out how the Risk Management, Control Process and Governance Process, which are functions of internal auditing are being recognized today at high level in many organizations, especially in public Sectors, when well structured and given the required mandate to perform, improves performance and serves as valuable contributors in Promoting good governance in its functions which are accountability, transparency, effectiveness \& efficiency and responsiveness in the public institutions in Kenya. The research adopted both the descriptive and correlation research designs in order to be successful, where 370 out of 398 respondents, sampled from eighteen (18) public institutions, completed a structured questionnaire. The events were recorded; analyzed, interpreted and described by using SPSS version 20 and the specific tools that were adopted in order to identify the levels of contribution of Internal Audit in Good Governance in the public institutions, respondent responses were determined by their demographic profiles. Parametric statistics were used to derive a meaningful conclusion from the empirical data using tools like descriptive statistics, t-test and Pearson Correlation. The study concluded that there is a strong significant relationship between Internal Audit and Good Governance in Public institutions.
\end{abstract}

Keywords: Audit, Internal Auditing, Internal Control, Public Sector, Value Addition, Governance, Kenya

\section{Introduction}

Today globally, internal audit activity has the potential to provide to date unequalled tool to management in the conduct of their duties. This potential has been transformed into a challenge and embodied in the new definition of internal auditing from the institute of internal auditors (IIA, 2008).

In the past, managers in the public sector had a narrower range of expectations for the role of internal audit compared to managers in the private sector. This is why internal audit function in the public sector was dominated by pre-payment audits. Thus, internal auditors devoted most of their time to checking on individual transactions before the payments were made, mainly, to crosscheck the authenticity of the transactions to be paid for. (Asare T. 2008)

Internal auditors are seen more as faultfinders rather than solution providers or witch hunters rather than watchdogs, and partners in the government strive for organizational excellence.
However, in recent years internal auditing has developed a strategic dimension to become an essential component of public sector governance and financial management reforms in many developing countries. (Asare T. 2009).

In Kenya, the government established the Office of the Government Chief Internal Auditor (GCIA) based in the Ministry of Finance "as an apex oversight body to co-ordinate, facilitate and provide quality assurance for internal audit activities within Kenya public sector”. (PFM, 2011)

An internal audit that performs well is one of the strongest means to monitor and promote good governance system in an organization. Thus, good governance is considered as a tool that is used in order to achieve strategy of an organization (Belay, 2007). As a result, in many countries internal audit has received great attention and has become an important asset of government financial management for improvement of the 
government performance sector. In connection to this, the researcher targeted public enterprises in Kenya to assess the role of internal audit functions in promoting good public sector governance system.

Thus, to curb corruption and deliver quality service in the public sector, there is a need to promote internal audit for good governance and leadership. In other words, to develop transparency, it is mandatory to install internal audit function (IAF) in government programs and services as part of modern management control system. This in turn needs IAF itself to grow highly qualified human resource in the field.

The above-mentioned problems can be classified into two categories with some overlapping. First, the competency of internal auditor that leads to trivial audit finding, lack of professional development, repetitive audit work, and non-value added internal audit report. Second, structural problem (Weak Governance) in the form of assigned task that impair the auditor independency, and fear of losing promotion, job security, and wrong perception about internal auditors as faultfinders and their task as policing rather than auditing (PFM, 2011).

Above all, weak organizational governance brings: Poorly motivated and frustrated internal audit staff because of limited scope of audit, Lack of independence, and internal auditor can also suffer from low status that leads to inefficient and ineffective internal audit work (PFM, 2011).

The importance of internal audit function to promote good governance within public sectors is well noted by concerned governmental bodies and known scholars. Inadequate auditing and accounting is one of the root causes for corruption and inefficiency in the public sector of Kenya. If such root causes of corruption are not addressed appropriately, the Country's poverty reduction and development programmed will definitely face serious challenges (Belay, 2007)

Moreover, Gansberghe (2005) has also noted that one of the strongest means to monitor ethics and governance in government institutions can be through the audit function. These statements clearly indicate the contribution that internal audit function can have towards to the government's efforts of solving the macro problem, poverty, through effective public sector governance.

Since the independence of Kenya, there has been a critical problem about good governance in public institutions to date. Kenyan government summarized a long term economic development plan called "Vision 2030" with major aspiration to transform Kenya's economy into a middle income country. This will not be achieved unless we transform from a subsistence agriculture economy to a knowledge-based one (Economy), with high levels of savings and private investment led by good governance.

\subsection{Statement of the Problem}

Internal audit is facing many challenges, some of the challenges identified by the Ministry of Finance, in Internal Audit Manual are: lack of expertise leading to trivial auditing findings, lack of opportunity for professional development, repetitive audit routines which staffed members can predict, being assigned to tasked such as accounting and pre-control of expenditures with the internal auditor subsequently have to audit (conflict of interest), inability to insist on getting significant information because fears of losing promotion opportunities and job security (lack of independence), wrong perception of the audit function and auditors by the staff of the public body.

\subsection{Objectives}

\subsubsection{General Objective}

The overall objective of this research was to establish the role of internal auditing in promoting good governance in public institutions in Kenya.

\subsubsection{Specific Objectives}

i. To assess the above basic objective, the specific aims of the study focused on answering the following questions.

ii. To assess the quality of internal audit from the perspective of internal audit independence and Public governance.

iii. To examine the internal audit objectivity from the perspective of internal audit independence and corporate governance.

iv. To know the performance of internal audit independence and identify factors that affects the internal audit independence.

\subsection{Research Questions}

i. What are the factors that stimulate the IAF in the public sector to perform its role in enhancing good governance (if any) and to which level good governance is being applied?

ii. Is there any significant relationship between Internal Audit Function and Good Governance promotion?

iii. Is there any significant relationship between factors that stimulate the IAF in Public Institutions and level of good governance

\subsection{Study Hypothesis}

The researcher tested the following hypothesis.

$H_{0}$ : There is no significant relationship between Internal Audit Function and Good Governance promotion.

$H_{1}$ : There is no significant relationship between factors.

\subsection{Definition of Terms}

\subsubsection{Audit}

Referring to Hachette dictionary, "audit" is the operation intending to control the good management and safeguard the financial patrimony of an enterprise and application of correct and sounding decision making. (Pickett, 2010)

\subsubsection{Internal Audit}

Internal Audit is an independent and objective activity which gives the organization assurance of control on the level of its activities; it contributes advice and improves the value added. (UN, 2005) 


\subsubsection{Internal Control}

It refers to the group or a set of security measures which contribute to the control of an enterprise. It insures the protection and safeguards the patrimony and the quality of the information. On the other hand, it is the application instructions of direction and favoring the improvement of performance. (Barrett, 2002)

\subsubsection{Public Sector}

The public sector is that portion of society controlled by national, state or provincial, and local governments. The public sector overlaps with the private sector in producing or providing certain goods and services. The extent of this overlap varies from country to country, state to state, province to province, and city to city. This overlap is most often seen in waste management, water management, health care, security services, and shelters for homeless and abused people (IIA, 2006)

\subsubsection{Value Added}

Internal audit is intended to provide value to the organization by improving opportunities to meet the organizational objectives by identifying operational improvements, and by mitigating risks through objective assurance. Evolving features of internal auditing have brought some modifications to the definition of added value. For example, in a traditional approach, savings from the loss endured in public programs-plugging the hole-was a fundamental goal, compared with the present where delivering services effectively, efficiently, economically, and ethically have emerged as primary goals. (Ball, 2002)

\subsubsection{Good Governance}

In an organization, it is a tool to achieve organizational strategy. According to the professional guidance of the Institute of Internal Auditors (IIA), public sector governance encompasses the policies and procedures used to direct an organization's activities to provide reasonable assurance that objectives are met and that operations are carried out in an ethical and accountable manner. (IIA, 2007)

\section{Methods}

\subsection{Research Design}

This research adopted descriptive and analysis of variance to examine the role of internal audit in promoting good governance in public institutions in Kenya. Giovanis (2011), noted that descriptive and correlation methods are two of the five basic designs of quantitative methods of research. In this study the correlation was intended to investigate the interaction between Internal Auditing and Good Governance by using evidence from public institutions in Kenya.

\subsection{Theoretical and Conceptual Framework}

\subsubsection{Theoretical Framework}

There are two variables that were used in this Research: Independent variable: Internal Audit
Dependent variable: Good Governance

a) Internal Audit

The three main elements of Internal Audit are; Risk Management, According to the United Nation Audit Manual (UN, 2005), The internal audit activity should assist the organization by identifying and evaluating significant exposures to risk and contributing to the improvement of risk management and control systems.

Control, the internal audit activity should assist the organization in maintaining effective controls by evaluating their effectiveness and efficiency and by promoting continuous improvement.

Governance Process, the internal audit activity should assess and make appropriate recommendations for improving the governance process in its accomplishment of the following objectives: Promoting appropriate ethics and values within the organization, Ensuring effective organizational performance management and Accountability, Effectively communicating risk and control information to appropriate areas of the organization, Effectively coordinating the activities of and communicating information among the board, external and internal auditors and management. (IIA, 2006)

b) Good Governance

The United Nations (UN, 2005), in its work on public governance, focused in particular on the principal elements of good governance, namely: Accountability, Government is able and willing to show the extent to which its actions and decisions are consistent with clearly-defined and agreed-upon objectives. Transparency, Government actions, decisions and decision-making processes are open to an appropriate level of scrutiny by others parts of government, civil society and, in some instances, outside institutions and governments.

Efficiency and effectiveness, Government strives to produce quality public outputs, including services delivered to citizens, at the best cost, and ensures that outputs meet the original intentions of policymakers. Responsiveness, Government has the capacity and flexibility to respond rapidly to societal changes, takes into account the expectations of civil society in identifying the general public interest, and is willing to critically re-examine the role of government. (Herbert, 2010)

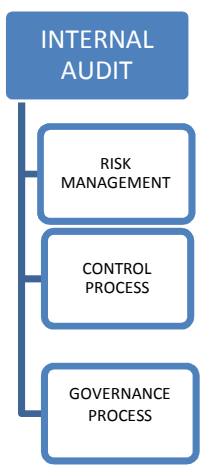
GOOD
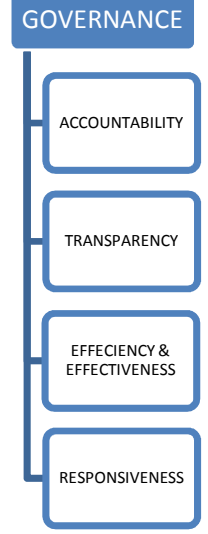

Figure 1. Conceptual Framework. 


\subsubsection{Conceptual Framework}

The theoretical framework was used as a basis for the development of the conceptual framework for this study, with service quality attributes and customer satisfaction as factors upon which the questionnaire for the study was based.

\subsection{Target Population and Sampling Techniques}

\subsubsection{The Population}

The government of Kenya is the biggest employer of internal auditors and involves several enterprises divided in many sectors. One of the earliest steps taken by the GOK in the direction of public service reform was the reduction of the number of Ministries and the carrying out of diagnostic studies of management systems.

The intended enterprises of public institutions are categorized in two main categories Ministries, Semi-autonomous entities and Government Business Enterprises, among those enterprises the researcher will investigated on the public institutions that were grouped in 9 sectors which are: Bank, Insurance, Energy and Transport, Industry, Pharmacy, Hotel, Air, Audit organizations and Semi-Autonomous organizations and all are under Ministries, Departments and Agencies (MDAs) by which the researcher selected purposively the employees and different committee members. The people selected have different responsibilities in those public institutions. All those organizations (public enterprises) were grouped in different strata according to their sector and will be randomly selected from those public enterprises in the sectors.

The target population for the current study includes the following:

1. Heads and staff of internal audit departments (IADs) of MDAs.

2. Other ordinary Staff of selected MDAs

3. Internal Audit services users(i.e. managements) of selected public enterprises

A total of about 100,000 people (all public workers) were considered as target population.

\subsubsection{Sampling Techniques}

The researcher adopted the survey type of research in which a sample of 398 from the target population of about 100,000. The following formula was used:

$$
n=\frac{N}{1+N(e)^{2}}=\frac{100000}{1+100000\left(0.05^{2}\right)}=398.406 \approx 398
$$

Where $\mathrm{n}$ is sample size required, $\mathrm{N}$ is the size of the target population, $\mathrm{e}$ is the margin error which is 0.05 . As indicated, the sample size for the population is: 398 and we used a multistage stratified sampling method to select elements.

\subsection{Validity, Reliability and Pilot Study of the Questionnaire}

The research instruments were tested for reliability. They had to be tested to check if they had the ability to yield the same results consistently when repeated measurements were taken under the same condition. A pilot study was conducted in selected Public Institutions.

The consistency reliability of the research instruments was determined by the use of Cronbach's Coefficient Alpha that is used to test internal consistency. The alpha provided a coefficient to estimate consistency of scores on an instrument when the items were scored as continuous variables (i.e. Disagree to Agree). While the reliability coefficient of 0.7 was acceptable the questionnaire designed by the researcher was sent to 7 experts for content validity and later used to determine the reliability coefficient.

\subsection{Development of Research Instruments and Data Gathering Procedures}

The study used a questionnaire for data collection. The questionnaire had three parts: the first part examined the profile of respondent and public institutions, the second concerned the internal auditing role in promoting governance, and the third concerned the good governance elements in relationship with internal auditing. Personal contact of the researcher with the respondents gave him the opportunity to explain when necessary to some respondents. Data was collected from the selected public institutions in Kenya between the months of March and May, 2015.

\subsection{Statistical Treatment of Data}

The data obtained was analyzed using SPSS version 20 and presented in the form of tables. Descriptive statistics such as frequencies, percentages, means, standard deviations, and Pearson product-moment correlation coefficient were used to analyze the data.

\section{Findings, Analysis and Interpretation}

\subsection{Profile of the Respondents}

The table below shows aspects that were taken into account with respect to the respondents profile.

Table 1. Company Distribution (Nature of Entity).

\begin{tabular}{lllll}
\hline & Frequency & Percent & $\begin{array}{l}\text { Valid } \\
\text { Percent }\end{array}$ & $\begin{array}{l}\text { Cumulative } \\
\text { Percent }\end{array}$ \\
\hline $\begin{array}{l}\text { Financial Institution } \\
\begin{array}{l}\text { Transportation, } \\
\text { Communication and } \\
\text { Power }\end{array}\end{array}$ & 150 & 40.5 & 40.5 & 40.5 \\
$\begin{array}{l}\text { Audit Institution } \\
\text { TOTAL }\end{array}$ & 122 & 26.5 & 26.5 & 67.0 \\
\hline
\end{tabular}

Table 1 above presents the distribution of the surveyed companies by the natures of Public institutions. They were basically three categories: Financial Institutions (Banks, Insurance, etc); Transportation, Communication and Power; Audit Institution. The distribution shows that $40.5 \%$ of respondents work in Financial Institutions and 26.5\% work for transportation, communication and power institutions, finally $33.0 \%$ work for audit institution.

Table 2 provide the distribution of the respondents 
organizations by age brackets whereby $5.9 \%$ of the surveyed organizations are aged between 1 and 5 years, $0.5 \%$ of the surveyed organizations are aged between 6 and 10 years, $11.1 \%$ are aged between 11 and 15 years while $77.0 \%$ are aged above 15 years and $5.4 \%$ were missing system. This implies that most of the organizations being surveyed are at their maturity ages in operations hence an appropriate choice to survey Internal Audit in Promoting Good Governance issues since most of the current organizations tend to lay more emphasis on public institutions aspects.

Table 2. Number of Years the Institution Has Been In Operation.

\begin{tabular}{llllll}
\hline & Frequency & Percent & $\begin{array}{l}\text { Valid } \\
\text { Percent }\end{array}$ & $\begin{array}{l}\text { Cumulative } \\
\text { Percent }\end{array}$ \\
\hline Valid & $\begin{array}{l}\text { BETWEEN } \\
1-5\end{array}$ & 22 & 5.9 & 6.3 & 6.3 \\
& $\begin{array}{l}\text { YEARS } \\
\text { BETWEEN }\end{array}$ & & & & \\
& 6-10 & 2 & .5 & .6 & 6.9 \\
& YEARS \\
& BETWEEN & & & & \\
& 11-15 & 41 & 11.1 & 11.7 & 18.6 \\
& YEARS & & & & \\
& ABOVE 15 & 285 & 77.0 & 81.4 & 100.0 \\
& YEARS & & & & \\
Missing & Total & 350 & 94.6 & 100.0 & \\
TOTAL & System & 20 & 5.4 & & \\
\hline
\end{tabular}

Table 3. Position in the Entity.

\begin{tabular}{llllll}
\hline & & Frequency & Percent & $\begin{array}{l}\text { Valid } \\
\text { Percent }\end{array}$ & $\begin{array}{l}\text { Cumulative } \\
\text { Percent }\end{array}$ \\
\hline Valid & $\begin{array}{l}\text { SENIOR } \\
\text { MANAGER }\end{array}$ & 18 & 4.9 & 5.9 & 5.9 \\
& MIDDLE & 40 & 10.8 & 13.1 & 19.0 \\
& MANAGER & & & & \\
& OPERATIONAL & 49 & 13.2 & 16.0 & 35.0 \\
& MANAGER & & & & \\
& AUDITOR & 128 & 34.6 & 41.8 & 76.8 \\
& EMPLOYEE & 71 & 19.2 & 23.2 & 100.0 \\
Missing & Total & 306 & 82.7 & 100.0 & \\
TOTAL & System & 64 & 17.3 & & \\
\hline
\end{tabular}

Table 3 provide the position the respondent in the entity; $4.9 \%$ of the respondents were senior managers, $10.8 \%$ were middle managers, $13.2 \%$ were operational managers, $34.6 \%$ were auditors while $19.2 \%$ were employees, also there were $17.3 \%$ missing system. This proves that the research was done with success because the majority of the respondents were the auditors.

Table 4. Gender

\begin{tabular}{llllll}
\hline & & Frequency & Percent & $\begin{array}{l}\text { Valid } \\
\text { Percent }\end{array}$ & $\begin{array}{l}\text { Cumulative } \\
\text { Percent }\end{array}$ \\
\hline Valid & MALE & 181 & 48.9 & 59.2 & 59.2 \\
& FEMALE & 125 & 33.8 & 40.8 & 100.0 \\
& Total & 306 & 82.7 & 100.0 & \\
Missing & System & 20 & 5.4 & & \\
TOTAL & & 370 & 100.0 & 100.0 & \\
\hline
\end{tabular}

By gender distribution, the study reveals, in this above Table 4 , that $48.9 \%$ of the respondents are male while $33.8 \%$ are female. This distribution is a near evenly distribution for both genders, thus a key indicator on the nature of board composition in organization in terms of gender, additionally the findings have a greater significance on the findings with regard to the role of gender on internal audit and good governance issues.

Table 5. Work Experience.

\begin{tabular}{llllll}
\hline & Frequency & Percent & $\begin{array}{l}\text { Valid } \\
\text { Percent }\end{array}$ & $\begin{array}{l}\text { Cumulative } \\
\text { Percent }\end{array}$ \\
\hline Valid & $\begin{array}{l}\text { BETWEEN } \\
1-5\end{array}$ & 71 & 19.2 & 23.4 & 23.4 \\
& $\begin{array}{l}\text { YEARS } \\
\text { BETWEEN } \\
\text { 6-10 }\end{array}$ & 112 & 30.3 & 36.8 & 60.2 \\
& YEARS & & & & \\
& BETWEEN & & & & \\
& 11-15 & 121 & 32.7 & 39.8 & 100.0 \\
& YEARS & & & & \\
Total & 304 & 82.2 & 100.0 & \\
Missing & System & 66 & 17.8 & & \\
TOTAL & & 370 & 100.0 & 100.0 & \\
\hline
\end{tabular}

The findings of this study indicates that $19.2 \%$ of the respondents have been with their respective organizations for a period between 1 and 5 years, $30.3 \%$ between 6 and 10 years and $32.7 \%$ between 11 and 15 years and $17.8 \%$ were missing system. This finding implies that the views of the respondents are reliable and vital given the duration of which they have been members of these organizations. Further, it implies that the respondents at least have some critical knowledge on the internal audit and good governance in these organizations.

\subsection{Statistical Analysis of Internal Auditing Role}

\subsubsection{Risk Management Analysis}

Results demonstrated that Risk Management was rated with a cumulative mean of $3.44(\mathrm{SD}=0.41)$ concerning the evaluation of the Public Institutions. The highest item is "In preventing Risk in your company, Protection of assets are Audit activities performed by your internal audit function" with a mean of 3.51 and a standard deviation of 0.60 . The item "The absence of good internal control increases an agency's risk of producing unreliable accounting data" was rated with a mean of 3.49 and a standard deviation of 0.55 . The item "Internal auditing of a system's internal control may decrease an agency's risk in a system" had a mean of 3.46 and a standard deviation of 0.52 . The item "The absence of sound internal control increases an agency's risk of non-compliance with laws or regulations" was rated with a mean of 3.41 and a standard deviation of 0.65 , the rating of this item was consistent with rating of the similar item "When you assess reliability and good conditions of financial information you prevent risk in your institution" rated with a mean of 3.41 and a standard deviation of 0.60 . The following item "The absence of sound internal controls increases an agency's risk of loss from fraud" was rated with a mean of 3.36 and a standard 
deviation of 0.77 . Based on result above, the public institutions of Kenya have the good systems of internal audit to ensure that the public institutions are well managed in terms of risk management.

\subsubsection{Control Process Analysis}

All the questions were positively confirmed with their means ranging from 3.08 to 3.74 . Generally, the study indicates with a mean of 3.50 standard deviation of 0.36 that is a cumulative concerning the control process. The implication of the aggregate score on control process indicates that the respondents perceived the aforementioned to be relatively high and this could influence cultural assimilation, attitude and the workers' behavior. Hence, each item score is analyzed and presented with their respective mean. In the highest item, the respondents tend to agree that "Internal Auditors in service trainings are organized whenever required" with a mean rating of $3.74(\mathrm{SD}=0.49)$. They also tend to agree, in the second item level, that "the organization allows internal auditor to identify and monitor risks against the achievement of organization's goal in auditing" at mean of $3.70(\mathrm{SD}=0.47)$. They tend to agree that "Internal audit function is strategically positioned to contribute to organizational strategy performance" with mean rating of $3.69(\mathrm{SD}=0.46)$ and they also tend to agree that "The internal auditors receive a plan ("planning memorandum") for each performance contract" with a mean rating of $3.66(\mathrm{SD}=$ $0.61)$. The item with the lowest mean was with a mean of 3.08 $(\mathrm{SD}=0.50)$, this means that the respondents tend to agree that "The organization's audit department have Staffs who have relevant experience".

\subsubsection{Governance Process}

Statistical results indicated that all items related to governance process were rated with a cumulative mean of 3.53 and standard deviation of 0.27 . The item with the highest mean of 3.79 and a standard deviation of 0.45 was "An internal audit performance verifies that the systems and procedures established" while the lowest item was "Designing and implementing internal control system are some of possible advisory" with a mean of 3.07 and a standard deviation of 0.62 . From the highest to the lowest, the following are the analysis and interpretation for other items. "The procedures for setting priorities concern the use of budgetary resources subject to a specific review" was rated with a mean of 3.78 and a standard deviation of 0.47 . The findings further indicate with a mean of 3.77 and a standard deviation of 0.47 that Ethical practices \& anticorruption programs are some of possible advisory roles of the internal audit to management applicable to your organization. Concerning the item "Sound business process (e.g. reengineering) is one of possible advisory roles of the internal audit to management applicable to your organization" the respondents tend to agree by a mean of 3.39 and a standard deviation of 0.70 . The item "The audit covers the relevance of the results assessment criteria established by management" had a mean of 3.36 and a standard deviation of 0.59 .

\subsubsection{Accountability}

Respondents perceived accountability to promote good governance with a cumulative mean of $3.42(\mathrm{SD}=0.40)$ and other items had their Means ranging from 3.61 to 3.31. The item with the highest Mean was Internal auditor focuses on Project Management while giving their opinion, with a Mean of 3.61 ( $\mathrm{SD}=0.72)$. This means that accountability in Public institutions is key elements for considerable in public institutional good governance.

\subsubsection{Transparency}

The study confirmed that the respondents perceived Transparency to promote good governance with a cumulative mean of 3.50(SD $=0.37)$ and other items had their Means ranging from 3.77 to 3.06. The item with the highest Mean was "There is utilization of appropriate technology to enhance the provision of internal audit services" with a Mean of 3.77 $(\mathrm{SD}=0.51)$. This means that transparency in Public institutions is one of the key elements for considerable in public institutional good governance. According to IFC (2009), accountability is one of two basic principles of good governance.

\subsubsection{Efficiency and Effectiveness}

The researcher administered six questions to assess the good governance in public institutions. The results yielded means ranging from 3.23 to 3.50 , with an average mean of 3.29 and standard deviation of 0.34 . The item with the highest mean was "There are enough internal audit facilities." with a mean of $3.50(\mathrm{SD}=0.61)$.

\subsubsection{Responsiveness}

To evaluate factors good governance in terms of responsiveness six items were tested and positively confirmed with means ranging between 2.91 and 3.21. The aggregate result yielded a mean 3.07 and a standard deviation of 0.43 . The item with the highest mean was "Internal auditors regularly review if their recommendations are put in practice." with a mean of 3.21 and a standard deviation of 0.76 . The lowest items "The corrective measures are usually taken as a result of weaknesses noted by the internal audit Department" and "The head of internal audit monitors and follows- up action taken by management to recommendations made by the audit function" were rated with a mean of 2.91 and a standard deviation of 0.82 .

\subsection{Correlation}

The study tried to check whether there was a significant relationship between perceptions on the role of internal audit functions on risk management analysis, control process analysis, and governance process and the evaluation rating of good governance promotion in terms of accountability, transparency, efficiency and effectiveness, and responsiveness.

The results in the table 13 represent the significant correlation among all variables by summarizing the values of Pearson's correlation coefficient that shows the correlation coefficient between Internal Audit Functions and Good Governance Functions within public institutions in Kenya; the correlation coefficient between Risk management function 
and Accountability, Transparency, Effectiveness \& Efficiency and Responsiveness showed that is rated between 0.186 and 0.606 with a p-value of 0.000 . The result shows that there is significant relationship between Accountability and Risk Management with the Pearson correlation of 0.458 , which shows that there is moderate correlation.

The findings indicate that Transparency and Risk Management are related with influences moderation with the coefficient of correlation of 0.606 ; the findings shows also that there is significant relationship between Effectiveness \& Efficiency and Risk Management with the Pearson Correlation of 0.369 , this shows that there is moderate correlation, finally it shows that there is significant relationship between Responsiveness and Risk Management with the Pearson correlation of 0.186 , which shows that there is weak correlation.

Table 6. Correlation Analysis.

\begin{tabular}{llllll}
\hline & & Accountability & Transparency & $\begin{array}{l}\text { Efficiency and } \\
\text { Effectiveness }\end{array}$ & Responsiveness \\
\hline Risk Management Analysis & Pearson Correlation & $.458^{* *}$ & $.606^{* *}$ & $.369^{* *}$ & $.186^{* *}$ \\
& Sig. (2-tailed) & .000 & .000 & .000 & .001 \\
& $\mathrm{~N}$ & 306 & 306 & 306 & 306 \\
Control Process Analysis & Pearson Correlation & $.399^{* *}$ & $.681^{* *}$ & $.247^{* *}$ & $-.150^{* *}$ \\
& & & & .008 \\
Governance Process & Sig. (2-tailed) & .000 & .000 & 306 & 306 \\
& $\mathrm{~N}$ & 306 & 306 & $.284^{* *}$ & -.039 \\
& Pearson Correlation & $.526^{* *}$ & $.383^{* *}$ & .000 & .500 \\
& Sig. (2-tailed) & .000 & .000 & 306 & 306 \\
\hline
\end{tabular}

**Correlation is significant at the 0.05 level

On the item of Control Process, the findings reveled that there is significant relationship between Accountability and Control Process with the Pearson Correlation of 0.399; between Transparency and Control Process, there is significant relationship with Pearson Correlation of 0.681 , these above to situation shows that there is moderate correlation. between Effectiveness \& Efficiency and Control Process is significant with Pearson Correlation of 0.247 , this shows that there is weak correlation; and there is significant relationship between Responsiveness and Control Process with the Pearson Correlation of -0.150 an with P-Value of 0.008 which is less than 0.05 , this shows again that there is weak correlation.

On the item of Governance Process, the results shows that there is significant relationship between Accountability and Governance Process with Pearson Correlation of 0.526, between Transparency and Governance Process with Pearson Correlation of 0.383 , between Effectiveness \& Efficiency and Governance Process with Pearson Correlation of 0.284 , between Responsiveness and Governance Process with Pearson Correlation of -0.039 and with P-value of 0.500 which is greater than 0.05 , in this case there is no significant relationship.

\section{Summary, Conclusions and Recommendations}

\subsection{Summary of Findings}

The research aimed to establish the relationship between this factors such us perceptions on the role of internal audit functions on risk management analysis, control process analysis, and governance process and the evaluation rating of good governance promotion in terms of accountability, transparency, efficiency and effectiveness, and responsiveness. In terms of nature of entity, a big number of 150 Respondents regarding Entity which represent $40.5 \%$ are in financial institutions, followed by 122 Respondents regarding Entities represent $33.0 \%$ are in Audit Institutions and the lowest number of 98 which represent $26.5 \%$ are in Transport, Communication and Power Energy Institutions. This showed that the Government of Kenya has put its effort in investment by using performance contracts and controls by using Monitoring and Evaluation to assess where they in implementing the vision.

In terms of age, a big number of 287 respondents, which represent $77.0 \%$, are in institutions, which are above 15 years, followed by 41 respondents representing $11.1 \%$ between 11-15 years old. This showed that the majority of public institutions is older and this aspect is positive for the institutions experiences; With regard to the position of the respondents 128 with $34.6 \%$ among them were Auditors and others were senior managers $(4.9 \%)$, middle managers (10.8\%), operational managers $(13.2 \%)$ and other employees with percentage of 19.2;

Regarding the risk management assessment as one of the internal audit items, the study the study revealed that all respondents tend to agree with the existence of risk management within public institutions by the average mean of 3.50 and on Control Process factor, in public institutions, the results yielded a mean of 3.50. This means that employees in public institutions in Kenya tend to agree with the existence of 
that item

Concerning Governance Process, all respondents rated the item with the average mean of 3.53 and this showed that public institutions employees tend to agree with the existence of Governance Process within public institutions in Kenya. Transparency in public institutions, all respondents rated the item with the average mean of 3.50; this showed that they tend to agree with the existence of transparency in Public Institutions in Kenya.

The study found out that, on effectiveness and efficiency, in public institutions, the results of this research showed that all respondents tend to agree, with mean of 3.29 that there is existence of effectiveness and efficiency. The other factor evaluated is Responsiveness, which had been rated with a cumulative mean of 3.07 ; this rate showed that employees in public institutions also tend to agree to this item.

The correlation coefficient between internal audit functions and good governance functions is between 0.19 and 0.61 , on Risk Management and Good Governance Factors, is between -0.15 and 0.68 on Control Process and Good Governance factors and is between -0.04 and 0.53 . There was a statistically significant relationship between perceptions on the role of internal audit functions on risk management analysis, control process analysis, and governance process and the evaluation rating of good governance promotion in terms of accountability, transparency, efficiency and effectiveness, and responsiveness within Public Institutions in Kenya.

\subsection{Conclusions}

With regard to respondent profile, the study revealed that the distribution of the surveyed companies by the natures of Public institutions. The distribution shows that $40.5 \%$ of respondents work in Financial Institutions and 26.5\% work for transportation, communication and power institutions, finally $33.0 \%$ work for audit institution. It was also observed that the distribution of the respondents' organizations by age and it implies that most of the organizations being surveyed are at their maturity ages in operations.

Finally Table 3 provide the position the respondent in the entity; $4.9 \%$ of the respondents were senior managers, $10.8 \%$ were middle managers, $13.2 \%$ were operational managers, $34.6 \%$ were auditors while $19.2 \%$ were employees, also there were $17.3 \%$ missing system. This proves that the research was done with success because the majority of the respondents were the auditors.

\subsection{Recommendations}

This study focused more on analysis of influence that the identified independent variable, which is Internal Audit, can have on the dependent variable, which is Good Governance, to promote it in the Kenyan Public institutions to enable the Kenyan Government to achieve their Goals summarized in Vision 2030. The study found that internal audit had the greatest effect on good governance within Kenyan Public institutions.

Based on the findings and conclusions, the following were recommended:

i. For the public institution to be effectively mitigate risk they should institute internal auditing in its operation.

ii. The public institutions have to accept internal auditing as a tool for effective internal control so as to realize their objectives set with ease.

iii. in order for the government to be effective in its operation and service delivery they should recognize more contribution of internal auditing,

\section{Acknowledgements}

We thank the participants of this study, their suggestions and comments.

\section{Nomenclature}

GCIA- Government Chief Internal Auditor

GOK- Government of Kenya

IAD- Internal Audit Department

IAF- Internal Audit Function

IIA- Institute of International Auditors

MDA- Ministries, Departments and Agencies

SPSS- Statistical Package for Social Scientists

\section{References}

[1] Asare, T. (2008). A study of the role of internal auditing in the public sector of Ghana: Governance and accountability. Birmingham, United Kingdom: Cornhill

[2] Ball, N. (2002). Enhancing Security Sector Governance: a conceptual framework of UNDP. UNDP

[3] Barrett, P. (2002). Expectation, and Perception, of Better Practice Corporate Governance in the Public Sector from an Audit Perspective. Melbourne: CPA Australia's Government Business Symposium

[4] Belay, Z. (2007 ). A study on effective implementation of internal audit function to promote good governance in the public sector. addis ababa, ethiopia.

[5] Gansberghe, C. N. (2005). Internal Audit: Finding its Place in Public Financial Management, Public Expenditure and Fiscal Accountability Programme. Washington D.C: World Bank.

[6] Giovanis, G. D. (2011). Evaluation of the Effectiveness of Internal Audit in Greek Hotel Business. International Journal of Economic Sciences and Applied Research , 19-34.

[7] Herbert Robinson, P. C. (2010). Governance \& Knoweledge Management For Public-Private Partnerships. southern Gate, Chichester, Weuissex, United Kingdom: John Wiley \& Sons, Ltd.

[8] IIA. (2008). International Standards for the Professional Practice of Internal Audit. Altamonte Springs, FL.

[9] INTOSAI . (2004). International Organization of Supreme Audit Institutions. Retrieved June 20, 2015, from http://www.intosai.org/Guidelines for Internal Controls Standards for the Public Sector. 
[10] MINECOFIN. (2011). Internal Audit Charter. PP. 1-14.

[11] PFM, S. P. (2011). Guidelines for Chief Budget Managers in Kenya

[12] Pickett, K. H. (2010). The Internal Auditing Handbook, Third Edition. Southern Gate, Chichester, West Sussex, United Kingdom: John Wiley \& Sons Ltd.
[13] Sawyer, L. B. (2003). Sawyer's Internal Audit 5th edition/ the Practice of Moderne Internal Auditing. Altamonte Springs, Florida: The Institute of Internal Auditors

[14] United Nations. (2005). The 2005 World Summit. The 2005 World Summit. New York: United Nations. PP.1-2. 